

\section{Sumário}

I. Dossiê Especial: Políticas públicas e boas práticas para o sistema penal ..................19

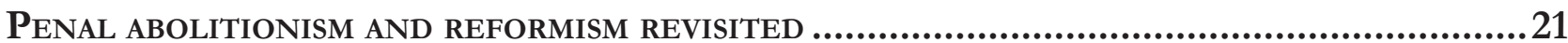

Roger Matthews

A FormulaÇão da AGENDA POlítico-CRIMINAL COM BASE NO MODELO DE CIÊNCIA CONJUNTA

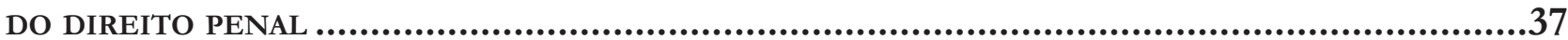

Mário Lúcio Garcez Calil e José Eduardo Lourenço dos Santos

TRIAL WiTHOUT UNDUE DELAY: A PROMISE UNFULFILLED IN INTERNATIONAL CRIMINAL COURTS..... 55 Cynthia Cline

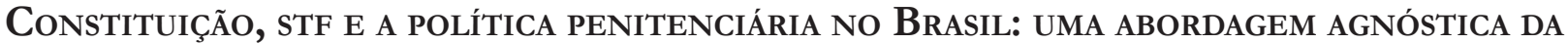

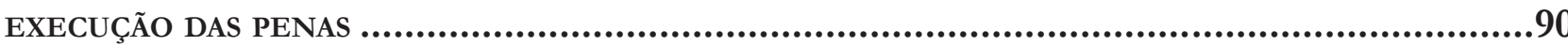

Bruno Amaral Machado e Rafael Seixas Santos

Prevenção especial negativa da Pena: o terreno FÉrtil Para A IMPlementaÇão e difusão DA LÓGICA ATUARIAL No SUBSISTEMA JURÍdICO-PENAL .............................................. 114

Paulo Afonso Cavichioli Carmona e Flávia Nunes de Carvalho Cavichioli Carmona

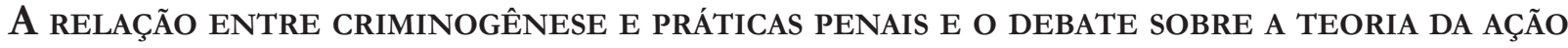
ENTRE SUBJETIVISTAS E OBJETIVISTAS ................................................................... 128

André Leonardo Copetti Santos e Doglas Cesar Lucas

A privatização de presídios e a ideia neoliberal de Criação de um Estado Mínimo ... 163 Gina Marcilio Vidal Pompeu e Carlos Lélio Lauria Ferreira

LA NECESIDAD DE INVESTIGAR LA PRISIÓN (DESDE AFUERA Y DESDE ADENTRO) PARA TRANSFORMARLA. Sobre UNAS MODESTAS EXPERIENCIAS EN EL Ámbito DE LA UNIVERSIDAD DE

Buenos Aires. 179

Gabriel Ignacio Anitua

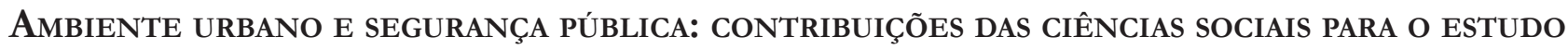
E A FORMULAÇÃO DE POLÍTICAS CRIMINAIS. 195 Sergio Francisco Carlos Sobrinho, Clóvis Eduardo Malinverni da Silveira e Aírton Guilherme Guilherme Berger Filho

ECOCÍDIO: PROPOSTA DE UMA POLÍTICA CRIMINALIZADORA DE DELITOS AMBIENTAIS INTERNACIONAIS OU TIPO PENAL PROPRIAMENTE DITO? 210

Djalma Alvarez Brochado Neto e Tarin Cristino Frota Mont' Alverne 
Selma Pereira de Santana e Carlos Alberto Miranda Santos

A JUSTIÇA RESTAURATIVA COMO INSTRUMENTO DE FORTALECIMENTO DA CULTURA DE PAZ: UMA NOVA PERSPECTIVA PARA A EXECUÇÃO DAS MEDIDAS SOCIOEDUCATIVAS NO BRASIL

Charlise Paula Colet Gimenez e Fabiana Marion Spengler

THE INTERNATIONALIZATION OF CRIMINAL LAW: TRANSNATIONAL CRIMINAL LAW, BASIS FOR A REGIONAL LEGAL THEORY OF CRIMINAL LAW 261 Nicolás Santiago Cordini

Crimes NA INTERNET E COOPERAÇÃo INTERNACIONAL EM MATÉria PENAL ENTRE Brasil E EsTADOS UNIDOS.

Guilherme Berti de Campos Guidi e Francisco Rezek

O PAPEL DA INTELIGÊNCIA FINANCEIRA NA PERSECUÇÃo DOS CRIMES DE LAVAGEM DE DINHEIRO E ILÍCITOS RELACIONADOS 290

Antonio Henrique Graciano Suxberger e Rochelle Pastana Ribeiro Pasiani

Política pública de Segurança dilacerada: o exemplo da Lei 13491/2017 E suas CONSEQUÊNCIAS PENAIS E PROCESSUAIS PENAIS

Luiz Gustavo Gonçalves Ribeiro

Atendimento INTEgRAL À Vítima: A SEgURANÇA PÚBLICA COMO DIREITO FUNDAMENTAL ......337 Waléria Demoner Rossoni e Henrique Geaquinto Herkenhoff

DiREitos FUndAMENTAIS E AS RELAÇõES ESPECIAIS DE SUJEIÇão. .361 Pedro Adamy

O NEAH E A ATENÇÃO AO AUTOR DE VIOLÊNCIA DOMÉSTICA E FAMILIAR CONTRA A MULHER EM BELÉM

Luanna Tomaz Souza, Anna Beatriz Alves Lopes e Andrey Ferreira Silva

Botão do pânico e Lei Maria da Penha.

Ludmila Aparecida Tavares e Carmen Hein de Campos

O que Pensam as juízas e os juízes sobre a aplicação da Lei Maria da Penha: um PRINCÍPIO DE DIÁLOGO COM A MAGISTRATURA DE SETE CAPITAIS BRASILEIRAS. Marilia Montenegro Pessoa de Mello, Fernanda Cruz da Fonseca Rosenblatt e Carolina Salazar I'Armée Queiroga de Medeiros

UMA SALA COR-DE-ROSA: A POLÍ́TICA PÚBLICA DE GÊNERO PREVISTA NA LEI 11.340/2006 NA Cidade de Piraquara - Paraná 450

Priscilla Placha Sá e Jonathan Serpa Sá 
A PRÁTICA DA MISTANÁSIA NAS PRISÕES FEMININAS BRASILEIRAS ANTE À OMISSÃO DO DIREITO À SAÚdE E A NEGAÇÃo DA DIGNIDADE HUMANA.

Elias Jacob de Menezes Neto e Tiago José de Souza Lima Bezerra

REPRESENTAÇÕES SOCIAIS NO SISTEMA DE JUSTIÇA CRIMINAL: PROTEÇÃO NORMATIVA E POLÍTICAS PÚBLICAS PARA O APENADO LGBT

Mariana Dionísio de Andrade, Marina Andrade Cartaxo e Daniel Camurça Correia

CALONS: REDEFININDO AS FRONTEIRAS DOS DIREITOS HUMANOS E DO SISTEMA DE

JUSTIÇA PENAL

Phillipe Cupertino Salloum e Silva e Marcos José de Oliveira Lima Filho

As AUdiênCIAS de CUSTÓdia No Brasil: uMA JANELA PARA A MELHORA Do CONTROLE EXTERNO DA ATIVIDADE POLICIAL 531

Carolina Costa Ferreira e Gabriel Antinolfi Divan

A atuaÇão do agente penitenciário como burocrata de nível de rua: PARA além da DISCRICIONARIEDADE

Thaís Pereira Martins e Camila Caldeira Nunes Dias

QUANDO A LUTA ANTIMANICOMIAL MIRA NO MANICÔMIO JUDICIÁRIO E PRODUZ DESENCARCERAMENTO: UMA ANÁLISE DOS ARRANJOS INSTITUCIONAIS PROVOCADOS PELA DEFENSORIA PÚBLICA NO CAMPO DA POLÍTICA PÚBLICA PENITENCIÁRIA E DE SAÚDE MENTAL...574 Patricia Carlos Magno e Luciana Boiteux

Penas alternativas para pequenos traficantes: os argumentos do TJSP na engrenagem DO SUPERENCARCERAMENTO. 605

Maíra Rocha Machado, Matheus de Barros, Olívia Landi Corrales Guaranha e Julia Adib Passos

II. OUtros temas

AÇão POPUlar POR OMISSÃo LESIVA AO MÍNIMO EXISTENCIAL (MORALIDADE) E CONTROLE DE POLÍTICAS PÚBLICAS: NOVOS HORIZONTES DESVELADOS PELA JURISPRUDÊNCIA DO STJ E DO STF NO PARADIGMA DOS DIREITOS FUNDAMENTAIS 632 Luciano Picoli Gagno e Camilo José d’Ávila Couto

As PRÁTICAS DE JURIDICIDADE ALTERNATIVA NA AMÉRICA LATINA: ENTRE O REFORMISMO E O impulso desestruturador a Partir de Stanley Cohen .649 Jackson da Silva Leal

Distinção InCONSISTENTE E SUPERAÇÃo de PreCEDENTES no Supremo Tribunal FEDERAL .668

Patrícia Perrone Campos Mello e Paula de Andrade Baqueiro 
DEMOCRATIZAÇÃo DO ORÇAMENTO PÚBLICO PELA DA LEGALIDADE, LEGITIMIDADE E ECONOMICIDADE

Rafael Antonio Baldo

A TRANSPARÊNCIA DA POLÍtiCA MONETÁRIA E A SUA LIMITAÇÃo aOS OBJETIVOS CONSTITUCIONAIS

Marcelo Quevedo Do Amaral

GESTÃO DOS ESPAÇOS MARINHOS NO CONTEXTO DAS ENERGIAS MARINHAS RENOVÁVEIS

Tarin Frota Mont`Alverne e Maira Melo Cavalcante

A APLICAÇÃo DO PRINCÍPIO DA PRECAUÇÃo ANTE OS RISCOS ADVINDOS DAS NOVAS TECNOLOGIAS BÉLICAS

Alice Rocha da Silva e Mario Abrahão Antônio

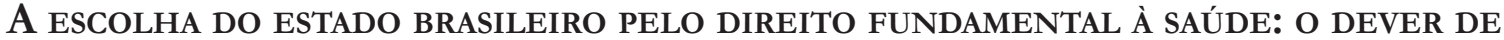
FINANCIAR MEDICAMENTOS DE ALTO CUSTO.

Andre Studart Leitão, Thiago Patrício de Sousa e Alexandre Antonio Bruno da Silva

Por que a ÁREA do direito Não TeM CUltura de PESQuisa de CAMPo No Brasil?

Fayga Silveira Bedê e Robson Sabino de Sousa 


\title{
Crimes na internet e cooperação internacional em matéria penal entre Brasil e Estados Unidos*
}

\author{
Crimes on the internet and international \\ cooperation in criminal matters between \\ Brazil and the United States
}

\author{
Guilherme Berti de Campos Guidi** \\ Francisco Rezek***
}

\section{* Artigo convidado}

** Mestre da Universidade de São Paulo em Direito Civil (2016); pós-graduado em Direito Digital Aplicado pela Fundação Getúlio Vargas (2016); doutorando em Direito Internacional e Comparado pela Universidade de São Paulo. Pesquisador para área de Privacidade do Instituto de Tecnologia e Sociedade do Rio de Janeiro (2016); pesquisador colaborador do Grupo de Ensino e Pesquisa em Inovação da FGV (2017); pesquisador do Núcleo de Estudos sobre Tribunais Internacionais da USP. Membro da International Association of Privacy Professionals, da Associação Brasileira para a Propriedade Intelectual, e da Academia Brasileira de Direito Internacional. Graduado em Direito pela USP (2012). Advogado. E-mail: <guilherme@franciscorezek.adv.br>.

*** Doutor da Universidade de Paris em Direito Internacional Público (1970). Diploma in Law da Universidade de Oxford (1979). Professor de Direito Internacional e Direito Constitucional na Universidade de Brasília. Diretor do Departamento de Direito (1974-1976) e da Faculdade de Estudos Sociais (1978-1979). Professor de Direito Internacional no Instituto Rio Branco (1976-1996). Professor na Academia de Direito Internacional de Haia. Procurador e Subprocurador-Geral da República (19721983). Ministro do Supremo Tribunal Federal (1983-1990, 1992-1997). Presidente do Tribunal Superior Eleitoral (1989-1990). Ministro de Estado das Relações Exteriores do Brasil (19901992). Juiz da Corte Internacional de Justiça das Nações Unidas (Haia, 1997-2006). Graduado em Direito pela UFMG (1966). Advogado. Email: <francisco@franciscorezek.adv.br>.

\section{Resumo}

A investigação de crimes cometidos na Internet, com o crescimento do número de ocorrências, tem gerado problemas em razão da descentralização da rede e da hospedagem de serviços digitais em outros países. O presente artigo procura trazer a lume a relevância dos acordos de cooperação judicial internacional (MLATs) para a investigação e persecução de crimes que tragam elementos internacionais em decorrência da utilização da Internet. Para tanto, analisamos os conceitos de soberania e jurisdição e sua relevância para a interação internacional judicial. Em seguida abordamos o MLAT vigente entre Brasil e Estados Unidos, considerando suas finalidades e fundamentos, suas peculiaridades, além das críticas feitas ao acordo. $\mathrm{O}$ trabalho não se pretendeu exaustivo no que toca teses atuais sobre a possibilidade de requisição direta de dados pelo Judiciário brasileiro, nem pretende o presente artigo trazer soluções pontuais para a reforma do acordo analisado, mas sim propor questionamentos e debates necessários para o aproveitamento do instituto no desenvolvimento de uma política criminal mais ampla. Como conclusão propomos o refinamento e expansão de tais acordos como medida de política criminal eficiente e justa para o tratamento de violações ocorridas na Internet.

Palavras-chave: Crimes cibernéticos. Internet. Cooperação Internacional. MLAT.

\section{Abstract}

The investigation of crimes committed on the Internet, with the rise of the number of cases, has created problems in law enforcement because of the decentralized character of the network and the hosting of digital services in other countries. The current article aims at bringing light to the relevance of mutual legal assistance treaties (MLATs) to the investigation and persecution of crimes that involve international elements come from the use of the Internet. For such, we analyze the concepts of sovereignty and jurisdiction and their relevance for the judicial international interaction. 
After we approach the treaty in force between Brazil and the United States, considering its finality and bases, its peculiarities, and the criticism it has received. This work does not intend exhaustive of all current theses regarding the possibility of direct request of data abroad by the Judiciary body of Brazil, nor does it aim at proposing specific changes to the text of the treaty, but we have tried to propose questions and debates necessary for the use of this legal institute in the development of broader criminal policies. As a conclusion, we propose that MLATs must be refined and expanded as a measure of efficient and fair criminal policy in the treatment of violations occurred on the Internet.

Keywords: Cyber Crimes. Internet. International Cooperation. MLAT.

\section{INTRODUÇÃO}

A Internet, grande invenção do milênio, é finalmente parte da sociedade. Seu alcance se expande diariamente, com mais e mais pessoas acessando a rede, usando seus serviços para trabalhar e se relacionar, para aprender e comunicar. Primeiro, de modo consciente e intencional, confiamos nossas vidas à tecnologia, nossos compromissos, projetos, relacionamentos, tarefas. Depois, a simbiose se manifesta - não vivemos sem nossos apps, telefonemas são mensagens de texto, afeto são fotos cheias de emojis, trabalho é o que entra sem parar na caixa de entrada, pessoas são pedidos de conexão. Dependência não é uma palavra forte demais para descrever o que ocorre.

Como é possível que um mundo assim utópico seja também lugar de maldades, fraudes, enganos? Ora, toda sociedade vem a se confrontar, naturalmente, com uma ou outra forma de criminalidade, ${ }^{1}$ não estando a Internet e o grupo de relações sociais dentro dela existentes imunes a isso: a sociedade da informação, entendida não como simples alusão ao valor da informação ${ }^{2}$ mas ao modo muito particular de (re)organização das relações sociais, tem sua também muito particular criminalidade.

A delinquência, em um cenário natural, pode ser tratada na forma geralmente adotada nos últimos séculos pelos Estados democráticos, com julgamento e sanção, diante da apuração dos fatos: materialidade e autoria contidos em determinado território, em determinada circunscrição, em um processo linear, concentrado. De certo modo, as mesmas mudanças operadas nas vidas dos usuários são as sentidas na persecução penal: os limites não são mais territoriais ou físicos, mas virtuais. O problema vem no confronto entre o que é essencialmente — necessária e obrigatoriamente — contido e o que, por natureza, não o é.

Nosso Direito é contido, como o são também nossas instituições e procedimentos; nossa maneira de endereçar a realidade com um comando legal está intrinsecamente ligada ao território. Estados dividem-se em suas fronteiras, jurisdições se pretendem universais, mas são limitadas por outras igualmente vocacionadas, a "comunidade" internacional, conglomerado de Estados e Organizações aferradas a suas soberanias, tem um largo caminho a percorrer até atingir a mesma integração mundial que a Internet nos deu em pouco mais de duas décadas.

Em termos objetivos, as características da Internet — sobretudo sua descentralização e sua distribuição indistinta por diversos territórios — nos impõem sérios desafios quando se trata de investigar, julgar e punir uma conduta criminosa. As provas ${ }^{3}$ de tais condutas, da materialidade e da autoria do crime, podem encontrar-se em máquinas a milhares de quilômetros de onde os efeitos do crime foram sentidos, ou de

1 BITENCOURT, Cezar Roberto. Tratado de direito penal. 5. ed. São Paulo: Saraiva, 2008. p. 1. v. 1.

2 SILVA, Carlos Bruno Ferreira da. Proteção de dados e cooperação transnacional: teoria e prática na Alemanha, Espanha e Brasil. Belo Horizonte: Arraes, 2014. p. 11.

3 A referência aqui é feita, por exemplo, a conversas por texto em determinada aplicação de computador, registros de acesso a um website ou rede social, arquivos armazenados "na nuvem", grupos fechados de discussão, dados cadastrais, ou qualquer outra manifestação do indivíduo em sua experiência na Internet. 
onde a conduta deve ser julgada. Na rede das redes, qualquer um, de qualquer lugar, pode ofertar serviços e produtos, lícitos ou ilícitos, a qualquer outra pessoa no mundo; mesmo as grandes empresas do setor reconhecem a sabedoria da distribuição de sua estrutura em países e territórios específicos, optando deliberadamente - e na maior parte dos casos, no gozo de seu pleno direito de fazê-lo — por submeter-se, talvez, não a uma única lei, mas, necessariamente, a uma única jurisdição.

Enquanto reconhecermos a necessidade de adaptação, mas não lutarmos pela implementação de novas mentalidades, o aparato estatal de repressão de condutas criminalizadas estará sempre a perder. Se é verdade que a mudança social clama pela submissão do Direito a novas ratios sociais, deve ela, também, trazer mudanças não apenas no Direito-produto-do-homem, mas no próprio homem, que deve aplicar a Lei. A razão deste artigo é justamente a proposta, ao menos parcial, de uma nova política criminal para a investigação de delitos na Internet, não olvidando que a mesma característica colaborativa presente no desenvolvimento da Rede $^{4}$ deve estar presente também no modo como o homem lida com ela.

Para tanto, é necessário um exercício de humildade que permita a compreensão de que a Justiça Brasileira não é onipotente nem poderia ser onipresente no mundo. Assim, avaliaremos, primeiramente, a questão da soberania e dos limites à jurisdição estatal. Compreender tais limitações implica a existência de mecanismos que permitam a um Estado superar sua impotência no estrangeiro, i.e., as vias normais da cooperação internacional, examinadas também neste trabalho.

Feito isto, deve-se considerar, com especial atenção, a via consensual dos tratados internacionais de mútua assistência judicial, relevantes que são no panorama atual como via facilitadora e padronizada de cooperação entre dois juízos de diferentes nacionalidades para atos de comunicação e instrução judicial. Como exemplo de estudo, analisaremos um tal acordo existente entre Brasil e Estados Unidos, que se encontra inclusive no centro de discussões judiciais sobre requisições judiciais de dados localizados no exterior. ${ }^{5}$

Ao final da exposição, espera-se atingir o objetivo de colocar em discussão uma política abrangente para lidar com elementos internacionais nas investigações e procedimentos criminais envolvendo crimes praticados na ou por meio da Internet, alterando, assim, a relação entre Direito e realidade, com votos de que tais questionamentos possam aproximar o que tende sempre a se afastar em tempos de revoluções sociais e tecnológicas cotidianas.

\section{SOBERANIA: JURISDIÇÃO E COOPERAÇÃO INTERNACIONAL}

A soberania é elemento formador do Estado moderno. ${ }^{6}$ Surgida na Idade Média, a ideia de soberania representou, àquele tempo, a consolidação da independência e poder de autotutela das nações em relação aos poderes então estabelecidos, ${ }^{7}$ como a Santa Sé e o Império Romano-Germânico. Diz-se soberano aquele

4 A esse respeito, confiram-se: CASTELLS, Manuel. A galáxia da internet. Rio de Janeiro: Zahar, 2003; e GUIDI, Guilherme Berti de Campos. A proteção dos dados pessoais na Internet: contribuições da experiência europeia ao modelo brasileiro. 2016.457 f. Dissertação (Mestrado) - Programa de Pós-Graduação em Direito Civil, Faculdade de Direito, Universidade de São Paulo, São Paulo, 2016. p. 47-51.

5 Em resumo, em diversos casos judiciais em curso a posição do Ministério Público, bem aceita pelo Judiciário, tem sido a da determinação de fornecimento dos dados buscados a subsidiárias e empresas do grupo econômico da empresa responsável por determinado serviço de Internet. Tais empresas, entretanto, resistem a essas determinações em razão das consequências nocivas da transferência desses dados para o Brasil sem uma decisão válida no território onde se encontram os dados, o que por sua vez acarreta na imposição de multas às empresas locais. Como exemplo, veja por exemplo BRASIL. Superior Tribunal de Justiça. Recurso em Mandado de Segurança n 55.019/DF. Quinta Turma. Rel. Min. Joel Ilan Paciornik, julgado em 12 de dezembro de 2017, Brasília, DJE de 01 de fevereiro de 2018.

6 “[...] o conceito de soberania é uma das bases da ideia de Estado Moderno, tendo sido de excepcional importância para que este se definisse, exercendo grau de influência prática nos últimos séculos, sendo ainda uma característica fundamental do Estado.” DALLARI, Dalmo de Abreu. Elementos de teoria geral do Estado. 27. ed. São Paulo: Saraiva, 2007. p. 74-75.

7 "Le principe de la souveraineté de l'État est aussi ancien que l'État lui-même. À l'origine, son rôle était essentiellement de con- 
ente político que não reconhece ou aceita autoridade superior a sua própria, ainda que reconheça conviver com pares igualmente soberanos. Assim, a soberania, na convivência, é elemento adstrito ao território, pois é com base nele que se define a área de exclusividade do Estado no exercício da força e imposição de autoridade.

Assim, é soberano aquele que é plenamente capaz de ditar a disciplina a reger a sociedade estabelecida em seu território, promulgando, executando e fazendo cumprir as leis àqueles que se encontrem sob seu domínio.

São características daquele que é soberano a independência, a liberdade para agir e a igualdade frente a seus homólogos. ${ }^{8}$ Não é ele, entretanto, absoluto nem incondicionado, pois é justamente por ser igual que, agindo soberanamente onde assim lhe compete, não pode o Estado deixar de reconhecer a mesma qualidade em seus iguais, impossibilitado de intervir em outrem enquanto não admite que no seu conduzir intervenham outros — por um princípio da não ingerência. ${ }^{9}$

É na igualdade soberana, pois, que se sustenta o princípio da reciprocidade do direito internacional. Por regra, não admite o soberano que outros pretendam dizer ou mandar no território onde exerce seu poder, mas pode o Estado, mediante comprometimento igualitário, escolher suportar algum grau de ingerência equivalente a fim de ter suas prerrogativas expandidas em relação à outra parte. ${ }^{10}$

\subsection{Jurisdição e seus limites}

O conceito de soberania abrange um grande número de ramificações, com consequências em muitos aspectos da formação e administração de um Estado (soberania interna), assim como em sua relação com outras nações (soberania externa). ${ }^{11}$ Interessa à discussão, entretanto, a manifestação da soberania no que diz respeito ao exercício do poder estatal: a jurisdição.

Jurisdiction concerns the power of the state to affect people, property and circumstances and reflects the basic principles of state sovereignty, equality of states and non-interference in domestic affairs. ${ }^{12}$

A jurisdição, em suma, refere-se ao poder do Estado de afetar pessoas, coisas e relações sob seu domínio, impondo a elas sua vontade, conforme os ditames da lei. Desse modo, a jurisdição não se refere unicamente ao sentido mais comum de "competência para julgar e ordenar", mas também ao poder de estabelecer normas e de administrar o Estado e adotar políticas. Nas palavras de Malcolm Shaw, podemos identificar a jurisdição normativa, a jurisdição executiva, e a jurisdição judicial:

Jurisdiction is a vital and indeed central feature of state sovereignty, for it is an exercise of authority which may alter or create or terminate legal relationships and obligations. It may be achieved by means of legislative action or by executive action or by judicial action. In each case, the recognized authorities of the state as determined by the legal system of that state perform certain functions permitted them

solider l'existence des États qui s'affirmaient en Europe contre la double tutelle du Pape et du Saint-Empire romain germanique." DINH, Nguyen Quoc; PELLET, Alain; DAILLIER, Patrick. Droit international public. 7. ed. Paris: L.G.D.J., 2002. p. 423.

8 "La souveraineté apparaît, dans ces conditions, comme la source des compétences que l'État tient du droit international ; celles-ci ne sont pas illimitées mas aucune autre entité n'en détient qui soient supérieures. Comme l'a rappelé la Chambre d'appel du Tribunal pénal international pour l'ex-Yougoslavie, "en droit international coutumier, les États, par principe, ne peuvent recevoir d"'ordres", qu'ils proviennent d'autres États ou d'organismes internationaux". La souveraineté reste bien l'attribut fondamental de l'État. À travers l'égalité souveraine, c'est l'indépendance de l'État qui est affirmée.” DINH, Nguyen Quoc; PELLET, Alain; DAILLIER, Patrick. Droit international public. 7. ed. Paris: L.G.D.J., 2002. p. 424.

9 "La notion de domaine réservé des États a pour conséquence l'interdiction faite aux autres États d’intervenir dans les matières qui en relèvent.” NGUYEN Quoc Dinh; PELLET, Alain; DAILLIER, Patrick. Droit international public. 7. ed. Paris: L.G.D.J., 2002. p. 441.

10 Sob esta sigla incluímos os tratados internacionais. É preciso cuidar, entretanto, que os acordos entre Estados não representam derrogação da soberania, mas sua realização, pela liberdade de agir no âmbito externo que decorre da própria soberania.

11 BONAVIDES, Paulo. Ciência política. 10. ed. São Paulo: Malheiros, 2003. p. 122-125.

12 SHAW, Malcolm N. International law. 5. ed. Cambridge: Cambridge University Press, 2003. p. 572-573. 
which affect the life around them in many ways. [...] These differences, particularly between the capacity to make law (the prescriptive jurisdiction) and the capacity to ensure compliance with such law (the enforcement jurisdiction), are basic to an understanding of the legal competence of a state. This is to some extent because jurisdiction, although primarily territorial, may be based on other grounds, for example nationality, while enforcement is restricted by territorial factors.

To give an instance, if a man kills somebody in Britain and then manages to reach the Netherlands, the British courts have jurisdiction to try him, but they cannot enforce it by sending officers to the Netherlands to apprehend him. They must apply to the Dutch authorities for his arrest and dispatch to Britain. ${ }^{13}$

Na prática, a jurisdição tem como limites básicos aqueles mesmos da soberania e é por ela também limitada (quando falamos da soberania de outros Estados). ${ }^{14}$

Não há reparos a fazer no exemplo de Shaw. O Estado que busque exercer seu poder de mando, veiculado por uma decisão judicial, sobre pessoa ou coisa localizada no exterior deve sempre pedir licença ao Estado estrangeiro, de modo que este, no exercício do seu próprio poder, avalize a decisão que se pretende ver cumprida, concedendo a ela a legitimidade que apenas a soberania do Estado estrangeiro pode conferir dentro de seu próprio território.

\subsection{Decisões estrangeiras e seus efeitos}

Uma decisão judicial pode ser conceituada como o resultado do exercício do poder estatal, uma solução imperativa para determinado conflito submetido ao Estado ${ }^{15}$ fundada no monopólio do uso legítimo da força pelo Estado ${ }^{16}$ e na função pública dessa condição. Trata-se de ato de coerção imposto às partes, submetidas que estão ao Estado.

É dizer, igualmente, que a decisão é ato que emana do uso legítimo do poder estatal de submeter coisas e pessoas a uma ordem. O componente da legitimidade é essencial, a diferenciar o Estado de outros arranjos autoritários. Isso implica, necessariamente, que o poder coercitivo da decisão judicial está diretamente atrelado à jurisdição: determinada decisão somente é válida enquanto baseada em um ordenamento jurídico vigente e aplicável; tal decisão só é exigivel ou imperativa enquanto o Estado deter o poder de obrigar seu cumprimento (por medidas constritivas, por exemplo). ${ }^{17}$

Como qualquer outro ato jurídico, sua caracterização jurídica depende do ordenamento jurídico em que é fundada. ${ }^{18}$ Assim, uma decisão estrangeira, até que seja validada pela ordem jurídica local, não passa de

13 SHAW, Malcolm N. International law. 5. ed. Cambridge: Cambridge University Press, 2003. p. 572-573.

14 "Três ordens de razões levam o legislador a limitar o exercício da jurisdição pelos órgãos judiciários [...]. Em primeiro lugar, está a convivência entre Estados soberanos, cada qual exercendo com exclusividade o poder estatal no âmbito de seu território — o que impede o juiz de uma causa de extrapolar fronteiras para impor atos imperativos fora dos lindes de seu país”. DINAMARCO, Cândido Rangel. Instituições de direito processual civil. 6. ed. São Paulo: Malheiros, 2009. v. 2. p. 529.

15 "Conceitua-se a jurisdição, a partir dessas premissas, como função do Estado, destinada à solução imperativa de conflitos e exercida mediante a atuação da vontade do direito em casos concretos. Falar em solução imperativa é pressupor a presença do poder estatal. O Estado persegue os objetivos do processo com fundamento em sua própria capacidade de decidir imperativamente e impor decisões (definição de poder estatal, segundo a ciência política), sem a necessidade de anuência dos sujeitos. A situação destes, perante o Estado que exerce a jurisdição, é de sujeição — conceituada esta como impossibilidade de evitar os atos alheios ou furtar-se à sua eficácia (Carnelutti). Esse é o significado da afirmação da jurisdição como função pública, regida por normas de direito público". DINAMARCO, Cândido Rangel. Instituições de direito processual civil. 6. ed. São Paulo: Malheiros, 2009. v. 1. p. 315-316. 16 WEBER, Max. Politics as a vocation. In: Essays in sociology. Nova Iorque: Oxford University Press, 1946. p. 77-128.

17 "Assim, com razão Tucci, quando explica que a jurisdição penal deve ser concebida como poder-dever de realização de Justiça Estatal, por órgãos especializados do Estado. Trata-se de decorrência inafastável da incidência do princípio da necessidade, peculiaridade do processo penal, inexistente no processo civil. Para tanto, é uma jurisdição cognitiva, destinada a conhecer da pretensão acusatória (e de seu elemento objetivo, o caso penal) para, em acolhendo-a, exercer o poder de penar que detém o Estado-juiz. Assim, é lugar-comum na doutrina vincular o conceito de jurisdição ao de poder-dever.” LOPES JÚNIOR, Aury. Direito processual penal e sua conformidade constitucional. 5. ed. Rio de Janeiro: Lumen Juris, 2010. v. 1. p. 427.

18 A esse respeito, consultar MELLO, Marcos Bernardes de. Teoria do fato jurídico: plano da validade. 8. ed. São Paulo: Saraiva, 2008. 
um fato, não produzindo efeitos jurídicos próprios. ${ }^{19}$ Apenas após o acolhimento de tal decisão como tal, mediante avaliação de sua compatibilidade com a ordem pública local, é que a decisão estrangeira, por uma delegação, pode ser executada. Onde um Estado não tem poder de mando, ali também as decisões judiciais por ele emanadas não serão exigíveis.

\subsection{Formas de cooperação internacional}

A disposição atual dos Estados soberanos não permite o simples avanço da jurisdição de um Estado sobre a de outro, razão pela qual deve-se recorrer à cooperação internacional. Entre elas encontramos as cartas rogatórias, o auxílio diplomático ou "bons ofícios", os acordos de cooperação judicial em diversas configurações e - ainda que não exatamente uma via de cooperação per se — os procedimentos de homologação de sentenças estrangeiras.

A carta rogatória consiste no mais básico instrumento de cooperação internacional. Trata-se de pedido feito pelo Judiciário de um país ao de outro Estado, rogando-lhe que dê execução aos atos ordenados na decisão original, sejam eles de comunicação ou instrução processual. ${ }^{20}$ Entre aqueles, podemos incluir as citações e as intimações de atos judiciais, entre estes a colheita de provas em geral, como a oitiva de testemunhas, a apreensão de documentos, o interrogatório do réu etc. Em regra, cartas rogatórias não são utilizadas para atos executivos ou constritivos, uma vez que é também costume no Direito Internacional que a jurisdição e competência para decidir sobre bens pertença ao Judiciário onde se localizam. ${ }^{21}$

Após emitida pelo juízo rogante, a carta é encaminhada por vias diplomáticas até o órgão correspondente, responsável pelo processamento desta. No Brasil, cartas rogatórias advindas de outros países são processadas pelo Superior Tribunal de Justiça por força do artigo 105, inciso I, alínea i, da Constituição Federal.

Uma segunda forma de cooperação relevante seria o auxílio diplomático ou, no costume internacional, "bons ofícios". Tal forma de interação entre duas nações não é específica da cooperação judicial, mas sim uma ferramenta geral e universal para o trato entre Estados. As relações diplomáticas são regidas pela Convenção de Viena sobre Relações Diplomáticas, de 1961. O instrumento, que traz os princípios sobre os quais se assenta a prática diplomática, entrou em vigor em abril de 1964 e foi promulgado no Brasil pelo Decreto ${ }^{\circ}$ 56.435 de 1965.

Não há oposição precípua à atuação diplomática para a cooperação judicial, seja em atos de comunicação e, principalmente, instrução processual. No entanto, a probabilidade de êxito em tal tipo de cooperação depende da existência de interesses mútuos em determinado desfecho em uma investigação criminal, por exemplo.

Devemos citar também o procedimento judicial de homologação de sentenças estrangeiras. Como já explicitado, tal procedimento serve para que uma decisão emitida em um Estado possa ser reconhecida,

19 As exceções a tal princípios podem ser estabelecidas individualmente por cada país, caso escolha por reconhecer automaticamente efeitos a determinado tipo de ato jurídico ou decisão judicial. O Brasil, por exemplo, reconhecia automaticamente efeitos às decisões declaratórias sobre estado de pessoas, considerando que a regência de tal assunto é quase sempre a da lei nacional do indivíduo. Tal regra, entretanto, antes prevista no parágrafo único do artigo 15 da Lei de Introdução às Normas do Direito Brasileiro (Decreto-Lei no 4.657/1942), foi revogada em 2009.

20 "Carta rogatória é a solicitação da cooperação jurisdicional de um órgão judiciário de outro país. O remetente da carta é rogante e o destinatário, rogado.” DINAMARCO, Cândido Rangel. Instituições de direito processual civil. 6. ed. São Paulo: Malheiros, 2009. v. 2. p. 531.

21 "Isso significa que pela via das cartas rogatórias somente se realizam atos de comunicação processual ou de instrução probatória. Salvo convenção internacional em contrário, da qual participem os Estados soberanos a que pertencem ambos os juízos, as cartas rogatórias não poderão ter por objeto os atos constritivos a serem realizados em território alheio. As rogatórias tramitam necessariamente por via diplomática, já traduzida para a língua do órgão destinatário, podendo ser processadas por outro meio quando assim dispuser um tratado internacional. A recusa de cumprimento rege-se pelas leis do país destinatário e eventual recurso contra ela será da competência de seus tribunais." DINAMARCO, Cândido Rangel. Instituições de direito processual civil. 6. ed. São Paulo: Malheiros, 2009. v. 2. p. 533. 
surtindo efeitos em outro Estado, concedendo este exequibilidade à decisão, fundada em seu próprio poder de mando, caso seja compatível com a ordem jurídica local. Os procedimentos de homologação, assim como o órgão competente para supervisioná-los varia a cada país, mas adota-se como regra geral que o procedimento de homologação não concorre com o juízo original: para avaliação da compatibilidade da decisão homologanda não pode ou deve o juízo da homologação reanalisar o mérito da questão, mas simplesmente se tal decisão viola a ordem pública, a soberania e os bons costumes do Estado onde se pretendem os efeitos do ato judicial estrangeiro. Intitula-se esse juízo de delibação, no qual a análise da decisão deve ser dar até os limites formais e de mérito do necessário para verificar se há ofensa a algum desses princípios. ${ }^{22}$

Por fim, devemos citar os tratados de mútua assistência judicial em matéria penal, ou MLATs, como são conhecidos (Mutual Legal Assistance Treaties). Tais tratados criam um procedimento abreviado de cooperação, definindo com clareza os passos necessários para a concessão de assistência internacional no trâmite de um processo que venha a afetar bens, pessoas ou relações localizados no território de uma das partes.

Um Estado que busque citar um indivíduo residente no exterior, ou executar medidas investigatórias ou instrutórias no estrangeiro, como um interrogatório, a apreensão de documentos ou a interceptação de comunicações, pode, por meio do procedimento descrito no tratado, transmitir ao Judiciário do país em questão seu pedido, já com todas as informações e documentos pertinentes e consciente dos critérios de avaliação para que tal ato de cooperação seja autorizado.

\section{Os ACORDOS DE COOPERAÇÃo JUDICIAL INTERNACIONAL - MLATS}

Analisaremos neste artigo o Acordo de Assistência Judiciária em Matéria Penal entre o Governo da República Federativa do Brasil e o Governo dos Estados Unidos da América, datado de 14 de outubro de 1997 e integrado à ordem jurídica brasileira pelo Decreto no 3.810 de 2001. O faremos por duas razões simples: em primeiro lugar, a análise de um instrumento convencional internacional apenas em tese tem uso limitado, por permitir uma análise genérica do instituto ou necessitar de recorrer à especulação; em segundo lugar, considerando que grande parte da "indústria da Internet" tem laços, data centers, ou sua sede nos Estados Unidos, é conveniente utilizar como exemplo o instrumento que provavelmente seria aplicável à maioria dos casos envolvendo requisições de dados eletrônicos mantidos no exterior.

\subsection{Fundamentos e pressupostos}

A função de um tratado, assim como a função de qualquer norma, é elemento sempre relevante para sua compreensão e aplicação. A interpretação sistemática é, nos campos mais complexos do Direito, ferramenta importante para coordenação de interesses e direitos conflitantes, permitindo a solução de aparentes conflitos normativos e servindo também para compreender certas escolhas legislativas.

Assim, é crucial compreender que os tratados de assistência judicial mútua e seus dispositivos específicos atendem a uma necessária composição de interesses e valores, por vezes contrapostos, e possuem, por si só, uma finalidade precípua. É sobre tais fundamentos que a legitimidade e o caráter justo de uma norma são estabelecidos.

22 "No juízo delibatório a cognitio desempenhada pelo magistrado é limitada em sua extensão, isto é, horizontalmente, pois tem sua área de incidência permitida restrita às questões jurídicas ou fáticas relativas aos exclusivos requisitos legais a que subordinada à homologação. Em perspectiva vertical, no entanto, a cognição sobre essas específicas questões não é superficial, ou sumária, mas profunda, ou exauriente, na medida em que o juiz não está sujeito a condicionamentos no trabalho intelectual voltado ao deslinde das questões cognoscíveis." ABBUD, Carlos de Albuquerque Cavalcanti. Homologação de sentenças arbitrais estrangeiras. São Paulo: Atlas, 2008. p. 125. Confira-se também: BRASIL. Superior Tribunal de Justiça. Sentença Estrangeira Contestada n 9.412/US. Corte Especial, Rel. Min. Felix Fischer, julgado em 19 de abril de 2017, DJE de 30 de maio de 2017. 
O MLAT, como dito outrora, é um instrumento cooperativo. Sua função no contexto da relação entre dois Estados é padronizar procedimentos e reduzir embaraços ao trânsito internacional de pessoas, bens, provas no contexto de investigações e procedimentos criminais. Cada uma das partes contratantes, na celebração de um tal tratado, espera poder obter com maior facilidade da outra elementos necessários para a correta e completa aplicação da Lei Penal em sua própria jurisdição, oferecendo à outra benefícios equivalentes. Se a motivação central baseada nas facilidades advindas do tratado parece ser a única realmente relevante, incorre-se em erro.

A padronização de procedimentos, mais que um benefício formal, atende a finalidade de suma importância: garantir que o pedido de cooperação, isto é, a pretensão de executar em um território a vontade de outro Estado, não viole preceitos fundamentais da ordem jurídica do Estado requerido. É por tal padronização, exigindo-se informações, documentos, justificativas, ações, que se estabelecem os elementos mínimos para análise de tal compatibilidade entre decisão e ordenamento legal; é por tal padronização que se elimina, sem maiores dificuldades, os atos investigativos e de instrução processual abusivos, injustificados, ilegais ou simplesmente contrários aos interesses soberanos do Estado requerido. Dá-se aqui vazão, prática e detalhada, à cláusula tão comum do Direito Internacional da exceşão de ordem pública.

\subsection{Contornos normativos}

O MLAT vigente entre Brasil e Estados Unidos estabelece que as partes se obrigam a prestar assistência mútua em matérias relacionadas com investigações, inquéritos, ações penais e prevenção de crimes. A delimitação material é relevante, pois parece indicar que, ainda que as partes desejem uma aproximação no exercício de suas jurisdições, reserva-se tal opção ao Estado, por seus órgãos de persecução criminal ou ao Poder Judiciário.

O objeto da colaboração pode incluir diversos atos inerentes a atividades de investigação e instrução, incluindo a tomada de depoimentos; o fornecimento de documentos, registros e bens; a localização ou identificação de pessoas ou bens; entrega de documentos; execução de pedidos de busca e apreensão; e qualquer outra forma de assistência não proibida pelas leis do Estado requerido. ${ }^{23}$

Os pedidos de assistência devem ser encaminhados por escrito, transmitidos de uma parte a outra por meio de autoridades centrais. No Brasil, a autoridade central designada é o Ministério da Justiça, cujo departamento responsável pelo processamento dos pedidos é o Departamento de Recuperação de Ativos e Cooperação Jurídica Internacional da Secretaria Nacional de Justiça (DRCI/SNJ/MJ). Nos Estados Unidos da América, cabe ao Attorney General, dentro do quadro do Department of Justice, a atuação como autoridade central.

O pedido de cooperação judicial deve (a) apontar a autoridade que conduz o inquérito, ação ou procedimento, (b) descrever os fatos sob investigação, a acusação e o histórico processual, (c) apontar as provas buscadas, (d) apontar os dispositivos legais aplicáveis e que fundamentam o pedido, (e) dizer exatamente o que se espera do Estado requerido a título de assistência e (f) o objetivo dessas diligências, a finalidade para qual a prova ou a providência solicitada é necessária (quais fatos a tornam necessária e que fatos a prova se presta a verificar), produzindo ainda os documentos que embasam o pedido de assistência, como a denúncia, a decisão judicial que se pretende ver cumprida e outras provas relevantes já colhidas.

Além dessas informações, exigíveis para qualquer pedido de assistência, o tratado exige também informações específicas a depender da providência solicitada, como a identificação e localização da pessoa que detém a prova buscada ou as perguntas a serem feitas a uma testemunha a ser interrogada. Os requisitos para outorga da assistência estão descritos no artigo 4 do Acordo, além de outros porventura presentes no regramento de cada país.

23 Artigo $1^{\circ}$. 
No que toca os crimes cometidos pela Internet, são de relevância as disposições do artigo XIII sobre entrega de documentos e do artigo XIV sobre busca e apreensão, pois aplicam-se diretamente à busca, obtenção e entrega de dados eletrônicos em posse de particulares ou entes da administração pública. Encontram-se ali regras especiais no que concerne aos atos de cooperação daquela espécie, como a exigência da manutenção da cadeia de custódia de provas já colhidas, exigíveis, cumulativamente, aos pressupostos gerais da assistência.

$\mathrm{Na}$ investigação de crimes cometidos na Internet, a maior dificuldade das autoridades brasileiras tem sido a obtenção de dados eletrônicos (como conteúdo de comunicações, mensagens, vídeos, material gráfico de violência ou pornografia infantil) mantidos em servidores no exterior. Nesse aspecto, quando venham a recorrer ao MLAT Brasil-Estados Unidos para obtenção de tais dados, devem ter atenção especial ao item 1 do artigo XIV:

Artigo XIV - Busca e Apreensão

1. O Estado Requerido executará o mandado de busca, apreensão e entrega de qualquer bem ao Estado Requerente, desde que o pedido contenha informação que justifique tal ação, segundo as leis do Estado Requerido [...].

É dizer, portanto, que os requisitos que autorizam a apreensão de dados eletrônicos a serem exigidos são aqueles previstos na lei norte-americana, e não na lei brasileira, no nosso exemplo. Nesse caso, o acesso e apreensão de tais dados deve se dar nos moldes estabelecidos pela Electronic Communications Privacy Act de 1986.

Relevante, nesse passo, é compreender que o pedido de assistência não implica cumprimento automático, qualquer que seja a solicitação. Entre as exceções explícitas do artigo III, a assistência solicitada será negada se (a) a solicitação referir-se a delito previsto na legislação militar, mas não constituir crime comum, se (b) o atendimento à solicitação prejudicar a segurança ou os interesses essenciais do Estado requerido e, se (c) a solicitação não for feita em conformidade com o Acordo. Verificada qualquer dessas hipóteses ou ainda se a solicitação puder interferir no curso de uma investigação ou ação penal no Estado requerido, este pode oferecer ao Estado requerente assistência condicionada, a fim de que os interesses de ambos sejam atendidos sem prejuízos de monta a nenhum.

Atos e decisões estrangeiros acaso lesivos aos valores e normas elementares do Estado serão rejeitados em nome da ordem pública, prerrogativa esta de qualquer nação soberana. ${ }^{24}$ Por tal razão, seguindo os padrões norte-americanos, é necessário que o pedido brasileiro de assistência apresente a causa provável, comparável em direito brasileiro à verossimilhança, que justifique a providência solicitada que venha a "violar" determinadas garantias constitucionais.

\subsection{Críticas correntes}

A via da cooperação judicial tem sido alvo de diversas críticas no Brasil. Em muitos casos, ${ }^{25}$ tais críticas advêm de um interesse em, simplesmente, justificar vias menos custosas e simples, como é o caso dos casos em que o Judiciário e o Ministério Público recorreram a argumentações centradas em uma suposta aplicação universal da Lei Brasileira por força do artigo 11 do Marco Civil da Internet, ${ }^{26}$ confundindo aplicaşão da lei com jurisdição, e consequentemente atribuindo ao juiz nacional o poder de obrigar empresas subsidiárias

24 Entende-se a ordem pública como aquela base social, política de um Estado, que é considerada inarredável para sobrevivência desse Estado; ou ainda como o conjunto de princípios implícita ou explicitamente conhecidos, na ordenação jurídica que, considerados fundamentais, excluem a aplicação do direito estrangeiro. Vide STRENGER, Irineu. Direito internacional privado. 3. ed. São Paulo: LTr, 1996. p. 449-450.

25 Como exemplo, confira-se: BRASIL. Superior Tribunal de Justiça. Recurso em Mandado de Segurança no 55.019/DF. Quinta Turma. Rel. Min. Joel Ilan Paciornik, julgado em 12 de dezembro de 2017, DJE de 01 de fevereiro de 2018.

26 Lei n ${ }^{\circ} 12.954 / 2014$. 
brasileiras a entregar dados em poder de suas empresas-mães, situadas no estrangeiro. Tudo o que já se disse, no Brasil e no estrangeiro, sobre soberania e jurisdição não precisa ser repetido para duvidar seriamente da autoridade desse argumento.

Outra via comum é a do ataque à efetividade da cooperação internacional e a suposta inconstitucionalidade que isso traria aos tratados dessa seara. A argumentação nesse caso é rasa, pois centrada no argumento de que tais tratados limitariam o poder estatal manuseado pelo Judiciário, impedindo-o de dar certas ordens e submetendo-o a um pedido obsequioso a outro Estado para ver cumpridas as ordens que efetivamente emitir. O Direito nos brinda diversas situações, entretanto, em que a simples dificuldade, burocracia ou regulamentação para o exercício de determinado direito subjetivo não levanta igual descontentamento a sustentar a expressão "inconstitucionalidade". ${ }^{27}$

A efetividade de um direito, entretanto, é sempre objeto válido de preocupação, desde que sua avaliação ou a busca por sua otimização se dê dentro das balizas maiores do Direito Constitucional e do Direito Internacional. No assunto em comento, emerge da análise a necessidade de sopesar a soberania dos Estados envolvidos, os direitos fundamentais protegidos, em um e outro países, que serão objeto de mitigação ou violação pela medida judicial, e o próprio interesse, de todas as partes envolvidas, na preservação do devido processo legal.

É assim, portanto, que qualquer proposta que busque diminuir a burocracia dos procedimentos de cooperação internacional expostos guarde sempre relação de preservação mínima com todos tais valores. Não se pode, assim, simplesmente, eliminar a necessidade de fundamentar a necessidade de determinada medida ou explicitar a finalidade de certa prova que se quer colhida, pois, sem tais informações, não poderia o Estado requerido verificar se a decisão objeto do pedido de cooperação viola direitos de seus cidadãos, e, consequentemente, sua própria prerrogativa soberana de aplicar suas próprias leis sobre seu território.

\subsection{Questionamentos}

A exposição acima encerra questionamentos necessários a fim de fortalecer o instituto da cooperação judicial internacional. Como defendemos, a investigação de crimes cometidos na Internet tem a sua disposição ferramentas viáveis para obtenção de dados eletrônicos mantidos no exterior. Não tem sido essa a prática dos tribunais, entretanto.

A política adotada pelos agentes do Estado brasileiro tem sido a da imposição de decisões de impossível cumprimento, fazendo com que as empresas estrangeiras envolvidas assumam o risco por desrespeitar as leis relativas a privacidade e proteção de dados pessoais a que estão submetidas em seus países-sede, violando direitos fundamentais garantidos por ordenamento estrangeiro sem o devido procedimento.

Caso tal política seja adotada universalmente, caminha-se para o caos. Enquanto tais condutas se popularizam, cresce a certeza de que o Brasil, principalmente arvorado na crença de que seu Judiciário é onipotente, não aceitaria que sua soberania fosse violada, caso os papéis fossem opostos.

Isso nos leva a questionar: em uma sociedade cada vez menos dependente de fronteiras para trabalhar, se comunicar, consumir e, em geral, viver, em razão das novas tecnologias, faz sentido que os Estados mantenham posição absolutista no trato da matéria? Não se fala aqui do abandono de preceitos fundamentais do Direito Internacional como soberania e jurisdição, pois estes continuam relevantes e essenciais à estrutura da nossa sociedade como tal, mas sim de passos firmes na direção do fortalecimento das vias cooperativas, a fim de tentar igualar em flexibilidade a sempre mutante tecnologia. Não seria, pois, o caso de investir na experiência cooperativa em vez da manutenção de posições absolutas e distanciadas? Pois, se, por um lado,

27 Como simples exemplos, considere-se as normas de Direito Processual, as exigências formais e materiais para uma condenação cível ou penal, os procedimentos administrativos necessários para a obtenção de passaporte, entre tantos outros. 
a defesa dos MLATs é criticada por sustentar a inviabilidade de outros caminhos com forte apego às ideias de soberania e jurisdição, não seria a posição daqueles que sustentam a soberania absoluta do Brasil para alcançar pessoas, bens, dados localizados fora de seu território somente por sua própria vontade ainda mais centralizadora e dependente de uma suposta primazia da soberania brasileira sobre outras?

Respostas definitivas não são aconselháveis, nesse momento, se o objetivo da discussão é o aprimoramento das instituições para que a investigação de crimes na Internet se dê sem maiores obstáculos.

O assunto, não obstante, merece sugestões concretas, uma vez que abordar deve tratar situações concretas e atuais, que certamente crescem em número nos tribunais de todo o país. Na linha de nossa exposição, parece natural que as sugestões sejam duas: o refino e a expansão. Refinar práticas e expandir a abrangência da cooperação judicial internacional são objetivos que contribuiriam não só para a melhor integração entre os Estados, mas também para o melhor andamento e distribuição de justiça pelo Judiciário.

\section{Considerações finais}

O estabelecimento de MLATs, certamente, é algo necessário em tempos de revolução tecnológica, mas, com a experiência em sua aplicação, deve vir, também, o refinamento de práticas, métodos, procedimentos. Não se trata de eliminar sem orientação requisitos e exigências que possuem raison d'être, mas sim de verificar, com base nas finalidades da norma e nos valores defendidos por cada disposição, quais dispositivos podem ser alterados, simplificados, melhorados ou detalhados para que o tratado como um todo possa melhor cumprir sua função social.

Por fim, é essencial que os esforços cooperativos sejam expandidos, tanto em número de tratados (ou quem sabe por tratados multilaterais), mas principalmente em abrangência. A via criminal, ultima ratio como é, aborda sempre as condutas mais desprezíveis de membros de uma sociedade, mas não é de longe a via mais efetiva em muitos casos. É possível, por exemplo, que determinada empresa prefira acionar outra empresa ou um ex-funcionário que tenham cometido um crime cibernético contra si no âmbito cível, em razão da maior agilidade e facilidade em obter a compensação adequada (talvez mais interessante que a punição do infrator).

Mecanismos acessórios de cooperação que permitissem a perseguição de dados eletrônicos no exterior por vias outras que não a criminal contribuiriam também para a redução do número de processos criminais e para um movimento de valorização da via criminal, submetendo a ela apenas casos cuja gravidade justificam duras penas. A cooperação judicial internacional, se adotada como política criminal para a Internet, tem então o potencial de fazer regredir o movimento amplo de criminalização de condutas, reservando o Direito Penal e as limitações graves a direitos fundamentais ao tempo em que forem realmente necessários.

\section{REFERÊNCIAS}

ABBUD, Carlos de Albuquerque Cavalcanti. Homologação de sentenças arbitrais estrangeiras. São Paulo: Atlas, 2008 .

BITENCOURT, Cezar Roberto. Tratado de direito penal. 5. ed. São Paulo: Saraiva, 2008. v. 1.

BONAVIDES, Paulo. Ciência política. 10. ed. São Paulo: Malheiros, 2003.

BRASIL. Decreto-Lei n $n^{0}$.657/1942, de 4 de setembro de 1942. Lei de introdução às normas do direito brasileiro. Disponível em: <http://www.planalto.gov.br/ccivil_03/decreto-lei/Del4657.htm>. Acesso em: 03 abr. 2018. 
BRASIL. Lei $n^{\circ}$ 12.954/2014, de 5 de fevereiro de 2014. Cria o Centro de Tecnologias Estratégicas do Nordeste, o Instituto Nacional de Pesquisa do Pantanal e o Instituto Nacional de Águas; altera a estrutura básica do Ministério da Ciência, Tecnologia e Inovação; cria cargos em comissão do Grupo-Direção e Assessoramento Superiores - DAS; altera a Lei no 10.683, de 28 de maio de 2003; revoga dispositivo da Lei $n^{\circ} 11.906$, de 20 de janeiro de 2009; e dá outras providências. Disponível em: < http://www.planalto.gov.br/ccivil_03/_ ato2011-2014/2014/lei/L12954.htm>. Acesso em: 3 abr. 2018.

BRASIL. Superior Tribunal de Justiça. Recurso em Mandado de Segurança n 55.019/DF. Quinta Turma. Rel. Min. Joel Ilan Paciornik, julgado em 12 de dezembro de 2017, Brasília, DJE de 01 de fevereiro de 2018.

BRASIL. Superior Tribunal de Justiça. Sentença Estrangeira Contestada n 9.412/US. Corte Especial, Rel. Min. Felix Fischer, julgado em 19 de abril de 2017, DJE de 30 de maio de 2017.

CASTELLS, Manuel. A galáxia da internet. Rio de Janeiro: Zahar, 2003.

DALLARI, Dalmo de Abreu. Elementos de teoria geral do Estado. 27. ed. São Paulo: Saraiva, 2007.

DINAMARCO, Cândido Rangel. Instituições de direito processual civil. 6. ed. São Paulo: Malheiros, 2009. v. 1.

DINAMARCO, Cândido Rangel. Instituições de direito processual civil. 6. ed. São Paulo: Malheiros, 2009. v. 2.

DINH, Nguyen Quoc; PELLET, Alain; DAILLIER, Patrick. Droit international public. 7. ed. Paris: L.G.D.J., 2002.

GUIDI, Guilherme Berti de Campos. A proteção dos dados pessoais na Internet: contribuições da experiência europeia ao modelo brasileiro. 2016. 457 f. Dissertação (Mestrado) - Programa de Pós-Graduação em Direito Civil, Faculdade de Direito, Universidade de São Paulo, São Paulo, 2016.

LOPES JÚNIOR, Aury. Direito processual penal e sua conformidade constitucional. 5. ed. Rio de Janeiro: Lumen Juris, 2010. v. 1.

MELLO, Marcos Bernardes de. Teoria do fato jurídico: plano da validade. 8. ed. São Paulo: Saraiva, 2008.

SHAW, Malcolm N. International law. 5. ed. Cambridge: Cambridge University Press, 2003.

SILVA, Carlos Bruno Ferreira da. Proteção de dados e cooperação transnacional: teoria e prática na Alemanha, Espanha e Brasil. Belo Horizonte: Arraes, 2014.

STRENGER, Irineu. Direito internacional privado. 3. ed. São Paulo: LTr, 1996.

WEBER, Max. Politics as a vocation. In: Essays in sociology. Nova Iorque: Oxford University Press, 1946. 
Para publicar na revista Brasileira de Políticas Públicas, acesse o endereço eletrônico www.rbpp.uniceub.br

Observe as normas de publicação, para facilitar e agilizar o trabalho de edição. 